\title{
CEREBRAL METABOLIC RECOVERY FROM DEEP HYPOTHERMIC CIRCULATORY ARREST AFTER TREATMENT WITH ARGININE AND NITRO-ARGININE METHYL ESTER
}

Takeshi Hiramatsu, MD ${ }^{a}$

Richard A. Jonas, MD $^{\mathbf{a}}$

Takuya Miura, $\mathrm{MD}^{\mathrm{a}}$

Adre duPlessis, $\mathrm{MD}^{\mathrm{b}}$

Masahiro Tanji, MD ${ }^{\mathrm{a}}$

Joseph M. Forbess, MD

David Holtzman, MD, $\mathrm{PhD}^{\mathrm{b}}$
Background: Recent studies suggest that nitric oxide is important in the pathogenesis of ischemic brain injury and also has a role in controlling cerebrovascular tone. This study examines the net effects of nitric oxide on cerebral metabolic recovery after deep hypothermic circulatory arrest. Methods: Two-week-old piglets were supported by cardiopulmonary bypass and cooled to $15^{\circ} \mathrm{C}$ followed by 1 hour of deep hypothermic circulatory arrest, 45 minutes of reperfusion and rewarming, and then 3 hours of normothermic perfusion. Groups of 10 piglets received one of four treatments before bypass: L-nitro-arginine methyl ester, inhibitor of nitric oxide synthesis, $10 \mathrm{mg} / \mathrm{kg}$ intravenously; L-arginine, to enhance nitric oxide synthesis, $30 \mathrm{mg} / \mathrm{kg}$ intravenously before bypass and then $10 \mathrm{mg} / \mathrm{kg}$ per minute during the first hour of reperfusion; a combination of L-nitro-arginine methyl ester pluS L-arginine at these same doses; and no pretreatment (controls). Cerebral high-energy phosphates and $\mathrm{pH}$ were measured by magnetic resonance spectroscopy in half the animals. Cerebral blood flow, metabolic rates for oxygen and glucose, and the oxidation/reduction state of cytochrome aa3 and oxygenated and deoxygenated hemoglobin measured by near-infrared spectroscopy were assessed in the other half of the piglets. Results: L-nitro-arginine methyl ester significantly increased cerebral vascular resistance and markedly reduced recovery of high-energy phosphates, $\mathrm{pH}$, and oxidation state of cytochrome aa3. L-arginine increased cerebral blood flow, cerebral glucose and oxygen consumption, and recovery of cytochrome aa3 oxidation and high-energy phosphates. L-Arginine did not reverse completely the effects of L-nitro-arginine methyl ester on cerebral metabolic recovery. Conclusion: In a piglet model of deep hypothermic circulatory arrest, L-nitro-arginine methyl ester has a deleterious effect and L-arginine has a beneficial effect on cerebral metabolic recovery. The deleterious metabolic effects of L-nitro-arginine methyl ester are only partially reversed by L-arginine. This fact suggests that there may be mechanisms in addition to inhibition of nitric oxide synthesis contributing to the neurotoxicity of L-nitro-arginine methyl ester in this model. ( $J$ Thorac Cardiovasc Surg 1996;112:698-707)
$N^{i}$ tric oxide plays important roles in the control of vascular tone in the brain, as well as neurotransmitter and second messenger roles both intraneuronally and interneuronally. ${ }^{1,2}$ Recent studies suggest that nitric oxide affects cerebral vasodilation under conditions such as hypoxia and seizures and after ischemia, ${ }^{1,3}$ as well as having a physiologic role in

From the Department of Cardiac Surgery, Children's Hospital, the Department of Surgery, Harvard Medical School, ${ }^{a}$ and the Departments of Neurology, Children's Hospital and Harvard Medical School, Boston, Mass.

Funded by a National Institutes of Health Resource Grant (RR-00995) and the Research Fund of the Department of Cardiac Surgery (Children's Hospital). the regulation of cerebral blood flow. ${ }^{4-6}$ Results of in vitro cell studies ${ }^{7,8}$ and studies with transgenic mice lacking neuronal nitric oxide synthase ${ }^{9}$ suggest that nitric oxide also contributes to the pathogenesis of cerebral ischemic damage. In vivo studies also

Received for publication Feb. 6, 1996; revisions requested March 6, 1996; revisions received April 3, 1996; accepted for publication April 4, 1996.

Address for reprints: Richard A. Jonas, MD, Department of Cardiac Surgery, Children's Hospital, 300 Longwood Ave., Boston, MA 02115.

Copyright (C) 1996 by Mosby-Year Book, Inc.

$0022-5223 / 96 \$ 5.00+0 \quad \mathbf{1 2 / 1 / 7 4 0 5 2}$ 
suggest a contribution of nitric oxide to perinatal ischemic brain damage. ${ }^{10,11}$

Cardiopulmonary bypass (CPB) and deep hypothermic circulatory arrest (DHCA) are applied clinically in neonates and infants to facilitate repair of congenital heart defects. Clinical studies have demonstrated permanent neurodevelopmental sequelae of the technique. ${ }^{12}$ Because deep hypothermia is dependent on adequate cerebral blood flow for homogeneous brain cooling and rewarming and because nitric oxide is a potent cerebrovascular dilator in addition to possibly being neurotoxic, we have studied the net effects of nitric oxide in our piglet model of DHCA. The experiments used $\mathrm{N}$ nitro-L-arginine methyl ester (L-NAME) to inhibit NO synthesis and L-arginine to enhance its synthesis. L-NAME is an arginine analog that readily crosses the blood-brain barrier and inhibits nitric oxide synthase, a group of isoenzymes that catalyze the synthesis of nitric oxide from L-arginine. ${ }^{13,14}$ Administration of L-arginine enhances nitric oxide synthesis. Therefore administration of L-NAME and L-arginine concurrently allows confirmation that the effects observed after L-NAME administration are entirely due to inhibition of nitric oxide synthase.

\section{Material and methods}

Animals. Forty Yorkshire piglets, 12 to 16 days old (mean 14 days) and 2.2 to $4.7 \mathrm{~kg}$ body weight (mean 3.9 $\mathrm{kg}$ ) were studied (Parson's Livestock, Hadley, Mass.). All studies were performed in compliance with the "Principles of Laboratory Animal Care" formulated by the National Society for Medical Research and the "Guide for the Care and Use of Laboratory Animals" prepared by the National Academy of Science and published by the National Institutes of Health (NIH Publication No. 86-23, revised in 1985).

Surgical preparation. Details of the surgical preparation and perfusion protocol have been described previously. ${ }^{15,16}$ The piglets were anesthetized with an intraperitoneal injection of methohexital ( $40 \mathrm{mg} / \mathrm{kg}$ ), tracheally intubated, and their lungs ventilated with $100 \%$ oxygen to achieve an arterial carbon dioxide tension between 35 and $45 \mathrm{~mm} \mathrm{Hg}$. Venous and arterial catheters were inserted through the femoral vein and artery into the thoracic vena cava and aorta. Anesthesia was maintained with continuous intravenous infusions of fentanyl $25 \mu \mathrm{g} / \mathrm{kg}$ per hour and pancuronium $0.1 \mathrm{mg} / \mathrm{kg}$ per hour after initial bolus injections. Temperature was monitored throughout the study by rectal and nasopharyngeal thermistors. Before $\mathrm{CPB}$ the temperature was maintained above $35^{\circ} \mathrm{C}$ with a heating lamp. Heart rate and blood pressure were monitored continuously. A bladder catheter was placed to monitor urine output.

The heart was exposed through a median sternotomy and the bypass cannulas were placed in the ascending aorta and right atrium. The piglet was given heparin (300 $\mathrm{IU} / \mathrm{kg}$ ) and a $5 \mathrm{~F}$ catheter was inserted through the right internal jugular vein to above the jugular bulb. CPB was then begun. An electromagnetic flow probe (Nihon Kohden, Tokyo, Japan) was placed in the arterial perfusion circuit to verify the pump flow. The pump circuit was primed with $400 \mathrm{ml}$ of 2-day-old homologous blood and $350 \mathrm{ml}$ of Normosol-R solution $\mathrm{pH} 7.4$ (Abbott Laboratories, North Chicago, Ill.) to achieve a hematocrit value of $20 \%$ to $25 \%$. Methylprednisolone $30 \mathrm{mg} / \mathrm{kg}$, cephazolin sodium $25 \mathrm{mg} / \mathrm{kg}$, and sodium bicarbonate ( $\mathrm{pH}$ 7.4) were added to the prime. The perfusate temperature was controlled by the heat exchanger with the oxygenator and a circulating water bath. During cooling, ice water was circulated in the water bath.

Perfusion protocol. CPB flow was set at $150 \mathrm{ml} / \mathrm{kg}$ per minute calibrated at a perfusate temperature of $37^{\circ} \mathrm{C}$. Cooling of the perfusate resulted in a $15 \%$ to $20 \%$ decrease in blood flow measured by the electromagnetic flowmeter. (This is most likely related to the change in compliance of the tubing in the pump-head raceway that occurs when the perfusate is cooled.) The alpha-stat strategy was used so that, as measured at $37^{\circ} \mathrm{C}, \mathrm{pH}$ was maintained at 7.40 by adjusting the flow of $100 \%$ oxygen. ${ }^{17}$ The piglet was perfused for 20 minutes at normothermia ( $37^{\circ} \mathrm{C}$ arterial temperature) to stabilize body temperature. Then the perfusate was cooled to an arterial temperature of $14^{\circ} \mathrm{C}$. Ice packs were placed around the head throughout the cooling and circulatory arrest periods. After 30 minutes of cooling, when nasopharyngeal temperature was $14.0^{\circ}$ to $15.0^{\circ} \mathrm{C}$, perfusion was stopped for 1 hour. Reperfusion was begun at $150 \mathrm{ml} / \mathrm{kg}$ per minute with the perfusate at $20^{\circ} \mathrm{C}$. After 45 minutes of reperfusion, by which time normothermia had been achieved, ventilation was restarted. Pump perfusion was continued for 3 hours with the perfusate temperature at $37^{\circ} \mathrm{C}$. During this 3 -hour period of perfusion, cardiac pulsatile assistance was achieved by raising central venous pressure minimally ( $<5 \mathrm{~mm} \mathrm{Hg}$ ). At the end of each study the animal was put to death by injection of Somelethal solution $1 \mathrm{ml} / 4 \mathrm{~kg}$ (J. A. Webster, Inc., Leominster, Mass.) and potassium chloride into the circuit.

Blood flow measurements. The baseline regional blood flow to the brain and other organs was measured by the radioactive microsphere technique 20 minutes after the initiation of CPB (normothermic baseline) and reflects the hemodilution of CPB, as well as any flow changes that may have resulted from the nonpulsatile nature of flow during CPB. Additional measurements were made 30 minutes after onset of cooling (at the end of hypothermic perfusion) and 15,45 , and 225 minutes after reperfusion after the 1-hour period of DHCA. ${ }^{18}$ Microspheres $(15 \mu \mathrm{m}$ in diameter) labeled with the isotopes iodine 125 , cerium 141 , tin 113 , strontium 85 , or scandium 46 were suspended in $0.5 \mathrm{ml}$ of $10 \%$ dextran and injected into a side port on the arterial tubing. Each injection contained about $2.5 \times$ $10^{6}$ microspheres. Blood $(5 \mathrm{ml})$ was withdrawn at a constant rate by syringe pump from the thoracic aorta catheter during and until 30 seconds after the microsphere injection. At the termination of the experiment, the brain, heart, lungs, kidneys, liver, adrenal glands, and intestines were removed and weighed. The brain was divided into 
Table I. Blood gases, hematocrit values, and nasopharyngeal temperatures (NP temp) in piglets receiving $L-N A M E$, L-arginine $(A R G)$, or L-NAME plus L-arginine $(N+A)$ as described in Methods; control animals received neither agent

\begin{tabular}{|c|c|c|c|c|c|c|c|c|}
\hline Parameter & Group & $\begin{array}{l}\text { Before } \\
\text { bypass }\end{array}$ & $N T$ & $H T$ & $R P(0)$ & $R P(15)$ & $N T(0)$ & $N T(180)$ \\
\hline \multirow[t]{4}{*}{ Arterial $\mathrm{pH}$} & Control & $7.48 \pm 0.02$ & $7.41 \pm 0.02$ & $7.39 \pm 0.02$ & & $7.43 \pm 0.03$ & $7.41 \pm 0.02$ & $7.40 \pm 0.02$ \\
\hline & L-NAME & $7.46 \pm 0.01$ & $7.38 \pm 0.02$ & $7.37 \pm 0.02$ & & $7.37 \pm 0.02$ & $7.37 \pm 0.01$ & $7.36 \pm 0.01$ \\
\hline & ARG & $7.45 \pm 0.03$ & $7.40 \pm 0.02$ & $7.43 \pm 0.03$ & & $7.43 \pm 0.02$ & $7.40 \pm 0.02$ & $7.36 \pm 0.03$ \\
\hline & $\mathrm{N}+\mathrm{A}$ & $7.43 \pm 0.02$ & $7.37 \pm 0.01$ & $7.37 \pm 0.02$ & & $7.39 \pm 0.01$ & $7.38 \pm 0.01$ & $7.39 \pm 0.02$ \\
\hline \multirow{4}{*}{$\begin{array}{l}\text { Arterial carbon dioxide } \\
\text { tension }(\mathrm{mm} \mathrm{Hg})\end{array}$} & Control & $38.2 \pm 1.1$ & $44.0 \pm 1.3$ & $43.9 \pm 1.1$ & & $39.6 \pm 1.6$ & $43.2 \pm 1.0$ & $43.0 \pm 1.0$ \\
\hline & L-NAME & $41.4 \pm 1.9$ & $42.5 \pm 1.1$ & $40.7 \pm 1.1$ & & $40.7 \pm 1.1$ & $42.7 \pm 0.8$ & $42.7 \pm 1.4$ \\
\hline & $\mathrm{ARG}$ & $38.8 \pm 2.8$ & $44.2 \pm 2.0$ & $42.1 \pm 1.4$ & & $39.4 \pm 1.9$ & $40.1 \pm 1.2$ & $40.5 \pm 1.1$ \\
\hline & $N+A$ & $37.9 \pm 0.7$ & $45.8 \pm 1.2$ & $42.0 \pm 1.2$ & & $40.2 \pm 1.5$ & $41.7 \pm 0.8$ & $44.1 \pm 0.8$ \\
\hline \multirow{4}{*}{$\begin{array}{l}\text { Arterial oxygen tension } \\
\quad(\mathrm{mm} \mathrm{Hg})\end{array}$} & Control & $522 \pm 54$ & $304 \pm 33$ & $764 \pm 64$ & & $335 \pm 58$ & $372 \pm 44$ & $431 \pm 37$ \\
\hline & L-NAME & $398 \pm 59$ & $402 \pm 46$ & $573 \pm 54$ & & $399 \pm 33$ & $345 \pm 43$ & $383 \pm 42$ \\
\hline & $\mathrm{ARG}$ & $438 \pm 23$ & $289 \pm 72$ & $830 \pm 45$ & & $316 \pm 44$ & $341 \pm 43$ & $380 \pm 28$ \\
\hline & $\mathrm{N}+\mathrm{A}$ & $430 \pm 44$ & $271 \pm 51$ & $694 \pm 49$ & & $268 \pm 43$ & $317 \pm 50$ & $332 \pm 11$ \\
\hline \multirow[t]{4}{*}{ Hematocrit value $(\%)$} & Control & $33.7 \pm 1.7$ & $25.4 \pm 0.6$ & $23.4 \pm 1.1$ & & $23.8 \pm 0.6$ & $24.0 \pm 0.9$ & $24.0 \pm 1.0$ \\
\hline & L-NAME & $33.3 \pm 0.9$ & $25.2 \pm 1.0$ & $23.5 \pm 0.8$ & & $22.6 \pm 0.6$ & $23.0 \pm 0.7$ & $22.4 \pm 0.8$ \\
\hline & $\mathrm{ARG}$ & $30.6 \pm 1.5$ & $24.5 \pm 1.0$ & $23.5 \pm 1.1$ & & $23.6 \pm 0.6$ & $23.5 \pm 0.6$ & $23.6 \pm 0.8$ \\
\hline & $\mathrm{N}+\mathrm{A}$ & $32.0 \pm 0.8$ & $26.8 \pm 0.9$ & $24.0 \pm 0.4$ & & $23.8 \pm 0.7$ & $23.5 \pm 1.1$ & $23.6 \pm 1.4$ \\
\hline \multirow[t]{4}{*}{ NP temp $\left({ }^{\circ} \mathrm{C}\right)$} & Control & $36.8 \pm 0.6$ & $36.6 \pm 0.7$ & $14.8 \pm 0.3$ & $17.9 \pm 0.5$ & $28.0 \pm 0.9$ & $36.2 \pm 0.9$ & $37.4 \pm 0.2$ \\
\hline & L-NAME & $36.7 \pm 0.1$ & $36.6 \pm 0.4$ & $14.7 \pm 0.6$ & $17.1 \pm 0.8$ & $28.1 \pm 0.9$ & $36.1 \pm 0.4$ & $36.9 \pm 0.2$ \\
\hline & ARG & $36.3 \pm 0.3$ & $36.6 \pm 0.3$ & $14.0 \pm 0.3$ & $16.6 \pm 0.5$ & $30.0 \pm 1.2$ & $36.1 \pm 0.4$ & $37.1 \pm 0.2$ \\
\hline & $\mathrm{N}+\mathrm{A}$ & $36.5 \pm 0.4$ & $37.1 \pm 0.3$ & $14.1 \pm 0.3$ & $16.6 \pm 0.7$ & $28.7 \pm 1.2$ & $36.9 \pm 0.3$ & $37.3 \pm 0.2$ \\
\hline \multirow[t]{4}{*}{ Rectal temp $\left({ }^{\circ} \mathrm{C}\right)$} & Control & $36.1 \pm 0.5$ & $36.7 \pm 0.6$ & $17.5 \pm 0.7$ & $23.1 \pm 0.8$ & $30.9 \pm 0.7$ & $35.1 \pm 0.3$ & $37.2 \pm 0.2$ \\
\hline & L-NAME & $36.5 \pm 0.3$ & $36.8 \pm 0.3$ & $19.2 \pm 0.9$ & $23.0 \pm 0.6$ & $29.5 \pm 0.8$ & $34.5 \pm 0.6$ & $36.8 \pm 0.3$ \\
\hline & $\mathrm{ARG}$ & $36.7 \pm 0.3$ & $37.0 \pm 0.3$ & $17.3 \pm 0.8$ & $23.1 \pm 0.5$ & $30.9 \pm 1.3$ & $34.3 \pm 0.9$ & $37.5 \pm 0.3$ \\
\hline & $\mathrm{N}+\mathrm{A}$ & $36.8 \pm 0.4$ & $37.3 \pm 0.2$ & $16.6 \pm 0.6$ & $22.1 \pm 0.5$ & $31.9 \pm 0.3$ & $35.0 \pm 0.8$ & $37.0 \pm 0.3$ \\
\hline
\end{tabular}

Before bypass, Before initiation of $\mathrm{CPB} ; N T$, after 20 minutes of normothermic perfusion; $H T$, at the end of hypothernic perfusion; $R P(0)$, immediately before reperfusion; $R P(15), 15$ minutes after beginning reperfusion; $N T(0)$, after 45 minutes of reperfusion and warming; $N T(180)$, normothermia for 180 minutes. Data are mean \pm standard deviation. There were no significant differences between groups.

five parts: the cerebral hemispheres, basal ganglia, midbrain, cerebellum, and brain stem (pons and medulla oblongata). The organs and blood samples were dissolved in $2 \mathrm{~N}$ potassium hydroxide-methanol solution and the radioactivity was counted (Compugamma 1282 , LKB Instruments Inc., Wallac, Finland). Blood flows were calculated from the rate of withdrawal of reference blood and the ratio of radioactivities in the tissues and the reference blood.

Metabolic measurements. Blood gas tensions, $\mathrm{pH}$, hemoglobin, plasma glucose, and lactate concentrations were measured in arterial and jugular venous blood before CPB and after each microsphere injection. Blood gases and hemoglobin were measured with a blood gas analyzer (Stat Profile 5, NOVA Biomedical, Waltham, Mass.). Plasma glucose and lactate concentrations were determined by the glucose oxidase method and enzymatic fluorometric micromethod, respectively. Cerebral oxygen consumption and glucose consumption were calculated from the total cerebral blood flow and the differences between the arterial and internal jugular venous oxygen and glucose concentrations. The oxygen content was calculated by the formula: Oxygen $=1.34 \times$ Hemoglobin $(\mathrm{gm} / \mathrm{dl}) \times$ Oxygen saturation $+0.003 \times$ Oxygen tension.

Magnetic resonance spectroscopy. Piglets studied by phosphorus 31-nuclear magnetic resonance spectroscopy underwent the same surgical procedure and CPB as described earlier. All studies were performed in an Oxford $40 \mathrm{~cm}$ horizontal bore superconducting $4.7 \mathrm{~T}$ magnet (Oxford Research Systems, Oxford, United Kingdom) at the Francis Bitter Magnet Laboratory (Massachusetts Institute of Technology). A $3.0 \mathrm{~cm}$ diameter copper surface coil was sutured to the scalp centered on the skull behind the supraorbital ridges. After placement, the coil was matched and tuned to the phosphorus frequency. Spectra were acquired in the Fourier transform mode on a custom-built spectrometer with an optimized excitation pulse of $100 \mu$ sec. Each spectrum was the average of 128 acquisitions with a 5 -second interpulse interval. The spectral width was $4000 \mathrm{~Hz}$. Relative concentrations of inorganic phosphate, creatine phosphate, and nucleoside triphosphate were determined from peak areas obtained by Lorentzian curve fitting and peak integration. Changes in adenosine triphosphate (ATP) were assessed from changes in $\beta$-nucleoside triphosphate peak, of which ATP contributes $60 \%$ to $70 \%{ }^{19}$ The inorganic phosphate, creatine phosphate, and nucleoside triphosphate changes are reported as percentages of the full-flow normothermic values after 20 minutes of CPB. The intracellular brain $\mathrm{pH}$ was calculated from the chemical shift of the inorganic phosphate peak relative to the creatine phosphate peak. ${ }^{20}$

Near-infrared spectroscopy. The near-infrared spectrometer used in this study was the NIRO-5 spectrometer (Hamamatsu Photonics KK, Hamamatsu, Japan). A small 


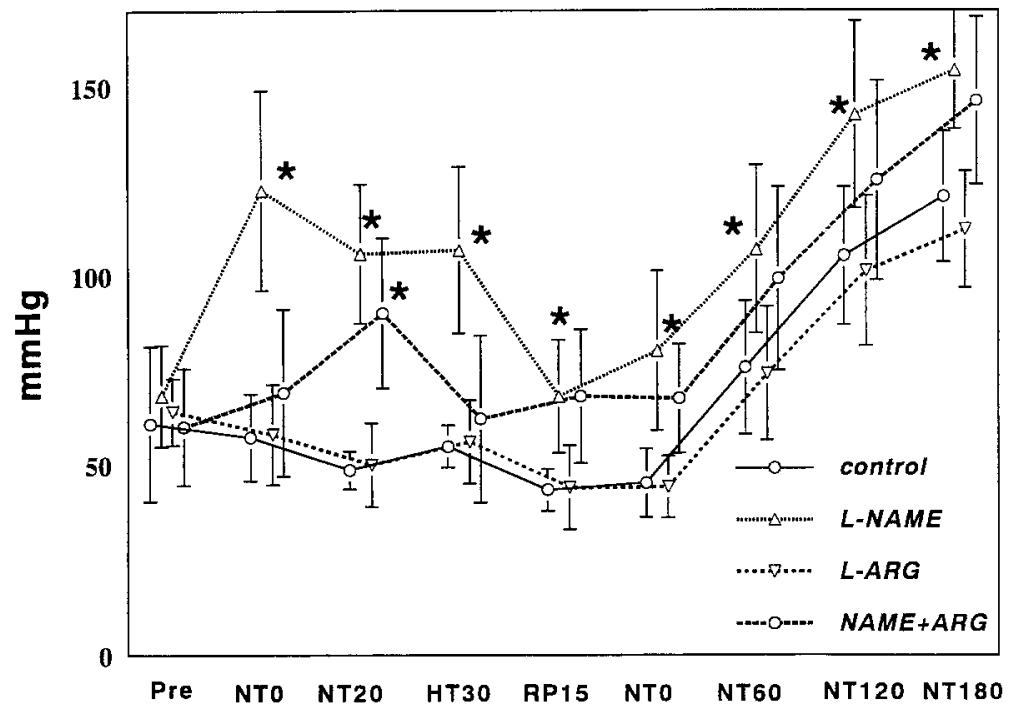

Fig. 1. Mean arterial blood pressures before and after deep hypothermic circulatory arrest in piglets treated with L-NAME, L-arginine $(A R G)$, or L-NAME plus L-arginine $(N A M E+A R G)$ are compared with results in untreated control piglets. The results are the mean \pm standard deviation for 10 animals in each group. The labeled time points are Pre (before placement on CPB); NT (normothermia before cooling); HT (after cooling to $15^{\circ} \mathrm{C}$ ); RP15 (15 minutes after beginning the postarrest reperfusion); NTO (45 minutes after beginning reperfusion when the temperature has reached $36^{\circ}$ to $37^{\circ} \mathrm{C}$ ); and $N T 180$ (after 3 hours of normothermic reperfusion). ${ }^{*}$ Difference from controls with a significance of $p<0.05$.

area of scalp was excised and plastic collars were glued directly to the skull. Fiberoptic optodes for transmission of laser light of near-infrared wavelengths and for photon detection were secured to the collars with plastic screws. The optodes were placed 3.0 to $3.5 \mathrm{~cm}$ apart in the coronal plane. The animal was then positioned supine with the head placed on a pillow designed to protect the optodes.

Concentration changes in brain oxygenated hemoglobin, reduced hemoglobin, and cytochrome aa3 were collected continuously from after induction of anesthesia to the end of experiment. Light was transmitted through the skull at four wavelengths: $776 \mathrm{~nm}, 828 \mathrm{~nm}, 848 \mathrm{~nm}$, and $913 \mathrm{~nm}$. Light was transmitted in sequential pulses at these frequencies. Photons emerging from the sample were collected by the second optode and counted by a photomultiplier tube. The difference between transmitted and received light intensity at each wavelength was used to determine optical density changes. Computer calculations based on chromophore absorption spectra then determined changes in oxygenated hemoglobin, reduced hemoglobin, and cytochrome aa3 concentrations in (mol/ L) - dpf according to the Beer-Lambert law. ${ }^{21-23}$ The term $d p f$ is the differential pathlength factor, which corrects the measured optode separation distance for light scattering within the sample. Because the dpf for piglet brain is not known, results are expressed in concentration change $\cdot d p f$. The dpf was assumed to be constant in each experiment. Near-infrared spectroscopy measurements were made with a sampling interval of 30 seconds.

Experimental design. Four groups were defined according to treatment before initiation of $\mathrm{CPB}$. Ten piglets received L-NAME $10 \mathrm{mg} / \mathrm{kg}$ intravenously before initia- tion of $\mathrm{CPB}$. A second group of 10 animals received L-arginine $30 \mathrm{mg} / \mathrm{kg}$ before $\mathrm{CPB}$ and then continuous intravenous infusion of arginine at a dose of $10 \mathrm{mg} / \mathrm{kg}$ per minute during the first hour of reperfusion. A third group of 10 animals received L-NAME plus L-arginine at the same doses and times. The control group of 10 piglets received neither of these compounds. In 20 piglets (five from each group) cerebral metabolic rates were determined by arteriovenous differences in oxygen and glucose, blood flows by radioactive microspheres, and oxygenation by near-infrared spectroscopy. The remaining five animals from each group underwent the same surgical and bypass procedures while being studied by phosphorus 31-nuclear magnetic resonance spectroscopy. Only measurements made at the end of normothermic perfusion, the end of cooling, and 15, 45, and 225 minutes after reperfusion were compared. Results are reported as a percentage of the measurements at the end of the initial normothermic CPB.

Statistics. All values are reported as mean \pm standard error of the mean. A statistical analysis system (SPSS, SPSS Inc., Chicago, Ill.) was used for all analyses. Repeated-measures analysis of variance and StudentNewman-Keuls test were used to detect differences between groups. A $p$ value less than 0.05 was considered significant.

\section{Results}

Baseline conditions. The initial conditions of piglets including blood gases, hematocrit values, and body temperatures were the same in all groups 

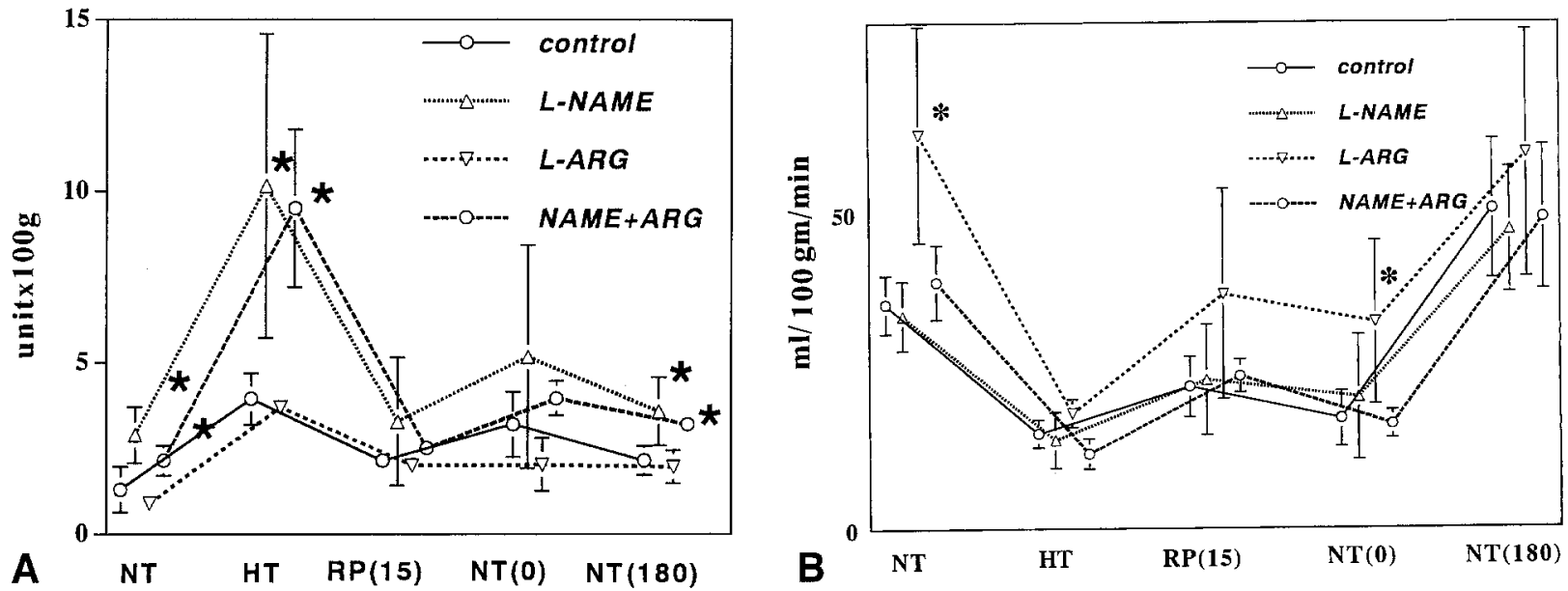

Fig. 2. Cerebrovascular resistance (A) and cerebral blood flows (B) before and after DHCA in piglets treated with L-NAME, L-arginine ( $A R G)$, or L-NAME plus L-arginine (NAME+ARG) are compared with results in untreated control piglets. The results are the mean \pm standard deviation for five animals in each group. Blood flows were measured by labeled microspheres as described in Methods. The time points are described in Fig. 1. *Difference from control animals with a significance value of $p<0.05$.

(Table I). Unless noted otherwise, all blood gas values are reported as being measured at $37^{\circ} \mathrm{C}$ without body temperature correction. When CPB was begun, hematocrit values decreased in all groups and reflected hemodilution by the pump prime. There were no differences in blood gas values, hematocrit values, and temperatures among the four groups throughout the experiment.

Mean arterial pressures and cerebral blood flows. Systemic arterial pressures were the same in control animals and in the three experimental groups before the drugs were administered (Fig. 1). After L-NAME, arterial pressures were significantly higher than in control animals. Blood pressures in piglets receiving L-NAME plus arginine were intermediate between L-NAME and control groups. After the hypothermic period, the arterial pressures in the two L-NAME groups remained higher than those in control animals. Blood pressures in the arginine-treated piglets and control animals were the same throughout the experiments. During the reperfusion period, the arterial pressures increased progressively above pre-CPB values in all four groups.

The total systemic blood flow calculated from the radioactivity in each microsphere injection and the reference blood correlated well with the pump flow measured by the electromagnetic flowmeter $(y=$ $0.98 x-7.3, r=0.945, p=0.001)$. Cerebrovascular resistance (Fig. 2, $A$ ) was increased at baseline during normothermic CPB after administration of L-NAME and was markedly elevated during cooling. Cerebral blood flow did not decrease, however, the reasons being the generalized increase in systemic blood pressure after L-NAME administration and the decrease in viscosity associated with the hemodilution of $\mathrm{CPB}$. The piglets treated with L-arginine had higher cerebral blood flows than did the control animals (Table II, Fig. $2, B)$. The cerebral blood flows were higher in this group before hypothermia and in the early reperfusion measurements. The L-arginine-treated piglets had higher blood flows than the control piglets in the cerebral hemispheres $(p<0.025)$, basal ganglia $(p<$ $0.025)$, and the midbrain $(p<0.05)$. Administration of L-arginine with L-NAME tended to reverse the vasoconconstrictive effect of L-NAME at baseline but not subsequently (Table II and Fig 2). In all groups, blood flow remained depressed after 15 and 45 minutes of reperfusion and rewarming. However, by 225 minutes cerebral blood flow exceeded the baseline in all groups except the arginine-treated piglets, in which it returned to (its elevated) baseline. Changes in regional brain blood flows were similar to those in global flows (not shown).

Cerebral high-energy phosphates and intracellular pH. Administration of L-NAME and initiation of normothermic CPB did not affect nucleoside triphosphate and creatine phosphate concentrations 

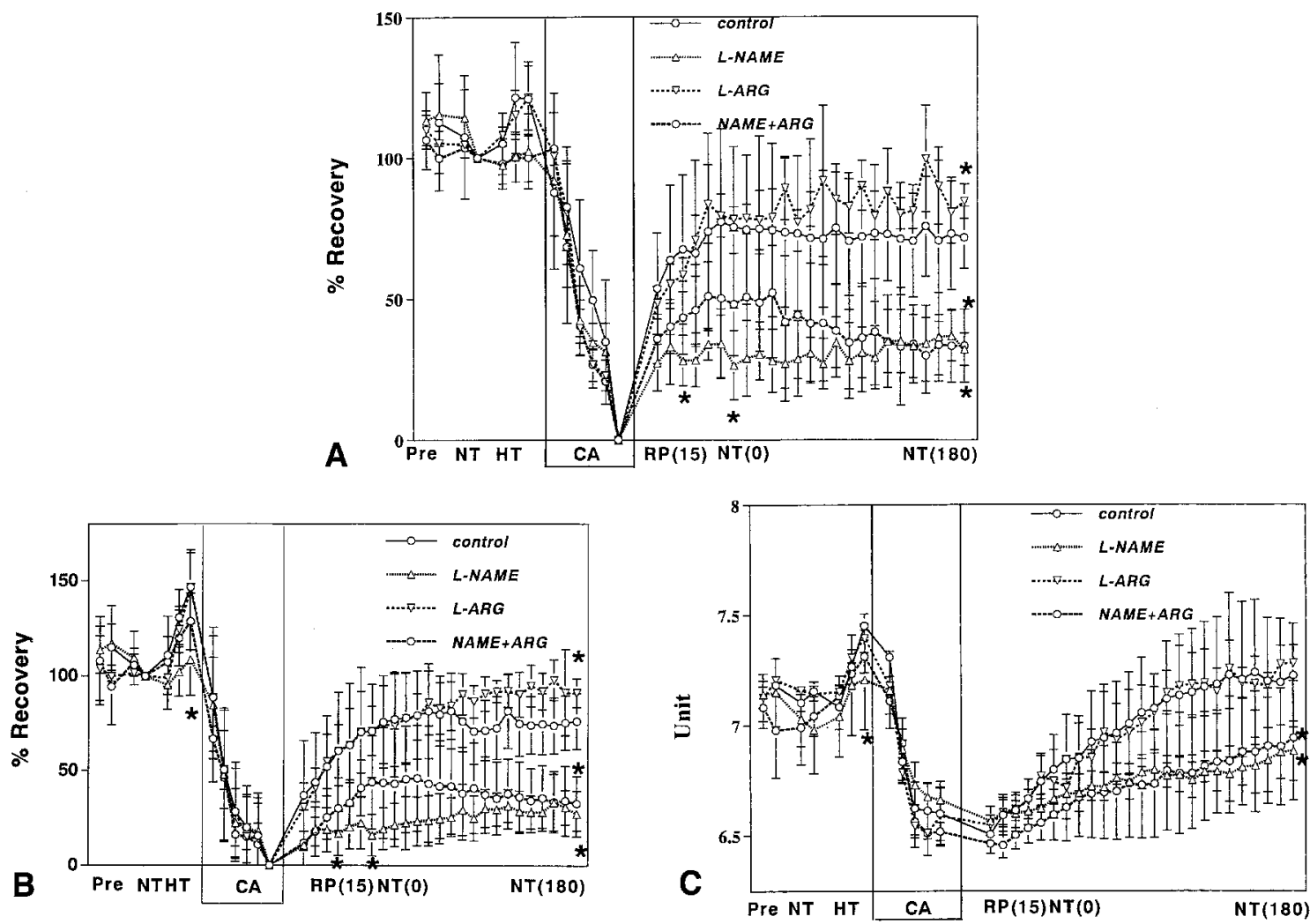

Fig. 3. The phosphorus 31-nuclear magnetic resonance spectroscopic measurements of cerebral nucleoside triphosphate (A), phosphocreatine (B), and intracellular $\mathrm{pH}(\mathbf{C})$ before and after DHCA in piglets treated with L-NAME, L-arginine $(A R G)$, or L-NAME plus L-arginine $(N A M E+A R G)$ are compared with results in untreated control piglets. Details of the NMR experiments are described in Methods. The results are the mean \pm standard deviation for five animals in each group expressed as a percent of the prehypothermic values $(N T)$. The time points are defined in Fig. 1. ${ }^{*}$ Significance value of $p<0.05$, shown only for the designated time points.

or $\mathrm{pH}$. Both nucleoside triphosphate and creatine phosphate increased whereas $\mathrm{pH}$ became more alkaline during cooling in control and L-arginine groups (Fig. 3). The L-NAME-treated group showed no increase in nucleoside triphosphate or creatine phosphate during cooling. The intracellular $\mathrm{pH}$ became alkaline during cooling in the L-NAMEtreated animals, but less alkaline than in control animals. Except for nucleoside triphosphate, all values were intermediate in the animals treated with L-NAME plus L-arginine.

Recoveries of high-energy compounds and of intracellular $\mathrm{pH}$ were markedly reduced in the brains of the L-NAME-treated group compared with recoveries in the control group (Fig. 3). The percent recovery of nucleoside triphosphate was about half the control value in the L-NAME- treated animals. Recoveries of creatine phosphate and intracellular $\mathrm{pH}$ after reperfusion were similarly reduced in L-NAME-treated animals. The intracellular $\mathrm{pH}$ was significantly more acidic after reperfusion in animals treated with L-NAME than in control animals.

The creatine phosphate and nucleoside triphosphate concentrations and intracellular $\mathrm{pH}$ were the same in arginine-treated piglets and control piglets before and during cooling (Fig. 3). The changes in nucleoside triphosphate, creatine phosphate, and $\mathrm{pH}$ during cooling were the same in piglets treated with L-arginine plus L-NAME as in those treated with L-NAME. After DHCA, recoveries of creatine phosphate, nucleoside triphosphate, and intracellular $\mathrm{pH}$ were greater and occurred sooner in L-arginine-treated piglets 
Table II. Baseline values for blood flows and glucose and oxygen consumptions in brains of piglets receiving $L-N A M E$; L-arginine $(A R G)$, or $L-N A M E+L$-arginine $(N+A)$, as described in Methods; control animals received neither agent

\begin{tabular}{lcccc}
\hline \multicolumn{1}{c}{ Parameters } & Control & L-NAME & ARG & $N+A$ \\
\hline Cerebral blood flow $(\mathrm{ml} / \mathrm{min} / 100$ gm tissue) & $35.6 \pm 2.1$ & $33.8 \pm 2.5$ & $62.4 \pm 8.8^{*}$ & $39.1 \pm 2.7$ \\
$\mathrm{CMR}^{\mathrm{O}} \mathrm{O}_{2}(\mu \mathrm{l} / \mathrm{min} / 100 \mathrm{gm}$ tissue) & $1.47 \pm 0.14$ & $1.31 \pm 0.17$ & $2.97 \pm 0.43^{*}$ & $2.16 \pm 0.14$ \\
CMR-glucose $(\mathrm{mg} / \mathrm{min} / 100 \mathrm{gm}$ tissue) & $6.14 \pm 0.72$ & $5.39 \pm 1.26$ & $13.66 \pm 0.72^{*}$ & $9.66 \pm 1.69$ \\
Systemic oxygen consumption $(\mu \mathrm{l} / \mathrm{min} / \mathrm{kg})$ & $4.30 \pm 0.32$ & $5.34 \pm 0.39$ & $7.42 \pm 0.69^{*}$ & $6.00 \pm 0.62$ \\
Systemic lactate level $(\mathrm{mmol} / \mathrm{L})$ & $3.24 \pm 0.38$ & $3.20 \pm 0.26$ & $3.70 \pm 0.35$ & $4.25 \pm 0.60$ \\
Regional blood flow $(\mathrm{ml} / \mathrm{min} / 100 \mathrm{gm}$ tissue) & & & & \\
Heart & $176.9 \pm 18.7$ & $210.5 \pm 12.6$ & $325.9 \pm 46.8^{*}$ & $258.7 \pm 39.4$ \\
Kidney & $119.3 \pm 17.5$ & $92.3 \pm 20.6$ & $120.2 \pm 29.2$ & $76.9 \pm 12.5$ \\
Liver (hepatic arterial) & $70.0 \pm 14.5$ & $87.2 \pm 25.0$ & $63.4 \pm 23.7$ & $61.1 \pm 10.4$ \\
Intestine & $47.8 \pm 5.2$ & $92.2 \pm 22.2$ & $128.7 \pm 31.9^{*}$ & $76.2 \pm 5.1$ \\
Lung (bronchial) & $8.8 \pm 2.8$ & $9.9 \pm 2.9$ & $11.8 \pm 3.0$ & $7.2 \pm 1.6$ \\
Adrenal glands & $469.6 \pm 55.3$ & $250.3 \pm 22.6$ & $608.4 \pm 84.5$ & $459.4 \pm 95.1$ \\
Carcass & $11.5 \pm 0.3$ & $14.0 \pm 0.9$ & $19.0 \pm 2.2$ & $14.4 \pm 0.45$ \\
\hline
\end{tabular}

$C M R$, Cerebral metabolic rate. Data are mean \pm standard deviation.

${ }^{*} p<0.05$ versus control animals.

than in control animals. In contrast, recovery of brain creatine phosphate and nucleoside triphosphate concentrations and intracellular $\mathrm{pH}$ was worse in piglets treated with L-arginine plus LNAME than in control animals, similar to the effects of L-NAME alone. Immediately after normothermic reperfusion, concentrations of brain high-energy phosphates and $\mathrm{pH}$ in the $\mathrm{L}$-arginine plus L-NAME group transiently increased compared with values in the animals treated with L-NAME alone.

Cerebral metabolic rates for oxygen and glucose. At all time points there were no differences in cerebral oxygen or glucose consumption between L-NAME-treated piglets and control piglets (Fig. 4). Cooling was associated with decreases in cerebral oxygen and glucose consumption to approximately $15 \%$ of baseline. Like cerebral blood flow, cerebral oxygen and glucose consumption remained depressed during early reperfusion, but after $180 \mathrm{~min}$ utes of normothermic reperfusion baseline values were regained in both groups. Blood lactate levels and systemic oxygen consumption were increased during the recovery period in the L-NAME and control groups (results not shown).

In contrast, both cerebral oxygen and glucose consumption were higher in the L-arginine-treated animals than in control or L-NAME-treated piglets (Fig. 4). These differences were significant only before hypothermia, but increased metabolic rates were present throughout the experiment. The results in the L-NAME plus L-arginine group tended to be intermediate between results in the L-NAME and in the L-arginine groups (Fig. 4).

Near-infrared spectroscopy. Administration of LNAME or L-arginine did not affect the pre-CPB values of oxygenated hemoglobin, reduced hemoglobin, or redox state of cytochrome aa3 (Fig. 5). The initiation of CPB was associated with hemodilution, causing falls in oxygenated hemoglobin and reduced hemoglobin that did not stabilize until 12 minutes after the onset of CPB. Cytochrome aa3 became slightly reduced during cooling in all groups. During DHCA there was a further decline in oxidation of cytochrome aa3.

During reperfusion cytochrome aa3 oxidation gradually returned toward baseline in control animals but remained reduced in the L-NAME-treated group. The differences between the cytochrome aa3 oxidation/reduction state in the L-NAME-treated group and the control animals became highly significant at 180 minutes of normothermic reperfusion.

The pigs treated with L-arginine had higher cytochrome aa 3 oxidation states than did control animals during reperfusion, with full recovery in both groups (Fig. 5). However, like the L-NAME-treated piglets, the L-NAME plus L-arginine group showed no recovery of cytochrome aa3 oxidation state during reperfusion.

Oxygenated hemoglobin increased during cooling in all groups. After the onset of DHCA there was progressive desaturation. The oxygenated hemoglobin and the reduced hemoglobin values were the same in all groups both during and after DHCA. 

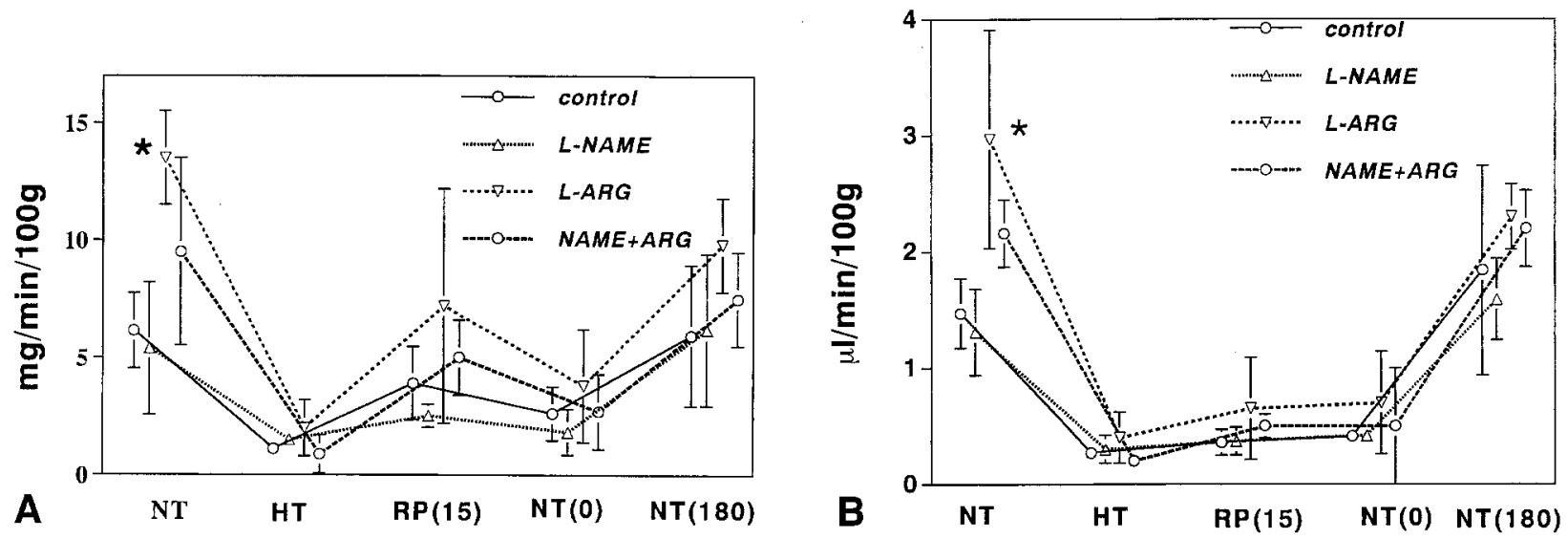

Fig. 4. Rates of cerebral glucose (A) and oxygen (B) consumptions before and after DHCA in piglets treated with L-NAME, L-arginine ( $A R G)$, or L-NAME plus L-arginine $(N A M E+A R G)$ are compared with results in control piglets receiving no treatment. Details of the metabolic rate calculations are given in Methods. The results are the means \pm standard deviation for five piglets in each group. The time points are given with Fig. 1. * Significance value of $p<0.05$

The oxygenated hemoglobin level was increased above baseline whereas the reduced hemoglobin value was at baseline after 180 minutes of normothermic reperfusion. Thus cerebral blood volume (oxygenated hemoglobin plus reduced hemoglobin) increased after DHCA comparably in all the treatment groups and the control group.

\section{Discussion}

This study demonstrates that L-NAME inhibition of nitric oxide synthesis increases cerebral vascular resistance during $\mathrm{CPB}$ and markedly reduces recovery of cerebral high-energy phosphates, $\mathrm{pH}$, and cytochrome aa3 after DHCA. Conversely, during normothermic CPB L-arginine increases cerebral blood flow, as well as cerebral glucose and oxygen consumption, and it increases recovery of cytochrome aa3 and high-energy phosphates after circulatory arrest. Thus in the specific setting of DHCA any deleterious effects of nitric oxide synthesized within neurons appear to be overwhelmed by the beneficial vasodilatory effects of nitric oxide synthesized within endothelial cells.

The results of this study are consistent with those of our previous study, in which the effects of two different doses of L-NAME on cerebral blood flow and metabolism before, during, and after circulatory arrest were evaluated. ${ }^{24}$ In the previous study also, L-NAME increased mean blood pressure, cerebral vascular resistance, and brain water content and did not cause measurable differences in cerebral blood flow. Under normal physiologic conditions administration of L-NAME results in decreased cerebral blood flow. However, CPB usually results in increased synthesis of vascular nitric oxide. ${ }^{25}$ Furthermore, the decrease in viscosity related to the hemodilution of the pump prime usually contributes to a marked decrease in blood pressure at the onset of CPB. However, in animals given L-NAME, blood pressure increased after the onset of $\mathrm{CPB}$ and cerebrovascular resistance increased, confirming effective inhibition of nitric oxide synthase at the dose used.

The effects of L-arginine in the piglet brain differ markedly from those observed with L-NAME. During $\mathrm{CPB} L$-arginine did not alter the arterial pressure but did increase cerebral blood flow. Arginine also significantly increased glucose and oxygen consumption in brain both before and after circulatory arrest. The post-DHCA recovery of cytochrome aa3 oxidation state was faster in arginine-treated piglets than control animals, in contrast to the persistent reduction seen in the L-NAME-treated piglets. Similarly, the phosphorus 31-nuclear magnetic resonance studies showed recovery of creatine phosphate and nucleoside triphosphate to be significantly greater and to occur earlier in the arginine group compared with both the L-NAME-treated animals and the control animals.

When the two treatments, L-NAME and L-arginine, were combined, arginine did not completely reverse the L-NAME inhibition of cerebral meta- 


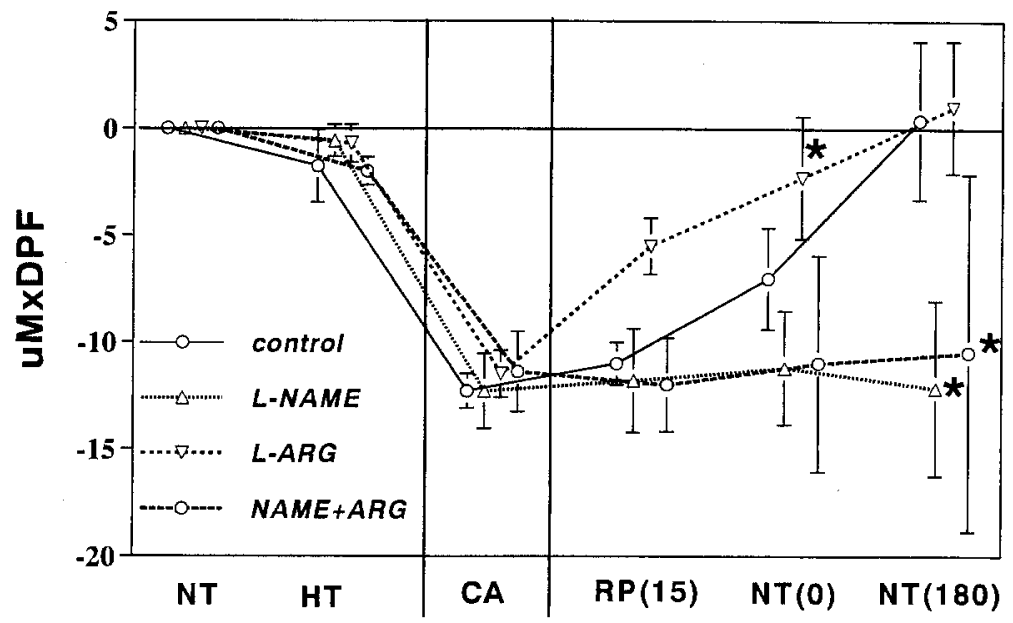

Fig. 5. Cerebral near-infrared spectroscopic measures of oxidation state of cytochrome aa3 in piglets receiving L-NAME, L-arginine $(A R G)$, or L-NAME plus L-arginine $(N A M E+A R G)$ are compared with results in untreated control piglets. Details of the measurement techniques are given in Methods. The results are the mean \pm standard deviation for five piglets in each group. The time points are given with Fig. 1. * Significance value of $p<0.05$.

bolic recovery. This may be a dose-related effect. For example, the arterial pressures and cerebral blood flows in piglets receiving the combined treatment were intermediate between the values with the individual treatments, consistent with competitive inhibition of arginine by L-NAME as a nitric oxide synthase substrate. An intermediate response also was seen in the oxygen and glucose consumptions before and after DHCA. Interestingly, in contrast, cytochrome aa3 remained severely reduced after the DHCA in piglets receiving the combined treatment. Similarly, recovery of creatine phosphate, nucleoside triphosphate, and intracellular $\mathrm{pH}$ was comparably depressed in the piglets receiving the combined treatment and L-NAME alone. The combined treatment did produce an early improvement of the metabolic recovery, but this effect was transient.

It is not clear why administration of arginine did not reverse the effects of L-NAME on cytochrome redox state and cerebral high-energy phosphates. L-NAME might be uncoupling oxidative phosphorylation and thus inhibiting ATP synthesis while producing a net reduction of the electron transport chain. L-NAME may have a direct effect on oxidative phosphorylation and ATP synthesis in addition to effects on nitric oxide synthesis. Both arginine and L-NAME might act as phosphogen precursors as analogs of creatine.
A number of reports have described possible roles for nitric oxide in the pathogenesis of cerebral ischemic injury. In neuronal culture, nitric oxide may participate in $N$-methyl-D-aspartate-mediated cytotoxicity by generating highly toxic free radical species. ${ }^{7,8}$ Despite these cytotoxic effects observed in vitro, nitric oxide has tissue-sparing effects based on antiplatelet, ${ }^{26}$ antileukocyte, ${ }^{27}$ directly quenching superoxide free radicals, ${ }^{28}$ and vasodilatory ${ }^{29}$ actions in vivo within ischemic tissue. Nitric oxide donors are neurotoxic if the redox state of the medium favors formation of $\mathrm{NO}^{-}$and are neuroprotective if the redox milieu favors $\mathrm{NO}^{+}$formation. ${ }^{30}$ Cell toxicity of nitric oxide also may be mediated by peroxynitrite formation, and a neuroprotective effect may be linked to S-nitrosylation of $N$-methyl-D-aspartate receptor thiol groups, a process resulting in downregulation of the $N$-methyl-Daspartate receptor and attenuation of $N$-methyl-Daspartate-mediated neurotoxicity. ${ }^{30,31}$

In conclusion, in this clinically relevant model of hypothermic global cerebral ischemia, L-NAME has a net deleterious effect and L-arginine has a net beneficial effect on cerebral metabolic recovery. The deleterious metabolic effects of L-NAME are only partially reversed by L-arginine, which suggests that there may be mechanisms other than inhibition of nitric oxide synthesis contributing to the neurotoxicity of L-NAME under these conditions. 
All work was performed at the Enders Laboratory (Children's Hospital, Boston) and the Francis Bitter Magnet Laboratory (Massachusetts Institute of Technology, Cambridge). Laura Young is thanked for her invaluable assistance in preparing the manuscript.

\section{REFERENCES}

1. Moncada S, Higgs A. Mechanisms of disease. The L-argininenitric oxide pathway. N Engl J Med 1993;2002-12.

2. Iadecola C, Pellegrino D, Moskowitz M, Lassen N. State of the art review article: nitric oxide synthase inhibition and cerebrovascular regulation. J Cereb Blood Flow Metab 1994; 14:175-92.

3. Rigaud-Monnet A, Pinard E, Borredon J, Seylaz J. Blockade of nitric oxide synthesis inhibits hippocampal hyperemia in kainic acid-induced seizures. J Cereb Blood Flow Metab 1994;14:581-90.

4. Sokoloff L, Kennedy C, Adachi K, Wang F, Takahashi S, Meltzer P. Effects of inhibition of nitric oxide synthase on resting local cerebral blood flow and on changes induced by hypercapnia or local functional activity. In: Krieglstein J, Oberpichler-Schwenk H, editors: Pharmacology of cerebral ischemia. Stuttgart: Wissenschlaftlich Vergalsgesellschaft, 1992:371-81.

5. Dirnagl U, Lindauer U, Villringer A. Role of nitric oxide in the coupling of cerebral blood flow to neuronal activation in rats. Neurosci Lett 1993;149:43-6.

6. Pellegrino D, Koenig H, Albrecht R. Nitric oxide synthesis and regional cerebral blood flow responses to hypercapnia and hypoxia in the rat. J Cereb Blood Flow Metab 1993;13:80-7.

7. Dawson VL, Dawson T, London E, Bredt D, Snyder S. Nitric oxide mediates glutamate neurotoxicity in primary cortical cultures. Proc Natl Acad Sci U S A 1991;88:6368-71.

8. Dawson VL, Dawson TM, Bartley DA, Uhl GR, Snyder SH. Mechanisms of nitric oxide-mediated neurotoxicity in primary brain cultures. J Neuroscience 1993;13:2651-61.

9. Huang Z, Huang PL, Panahian N, Dalkara T, Fishman MC, Moskowitz MA. Effects of cerebral ischemia in mice deficient in neuronal nitric oxide synthase. Science 1994;265:1883-5.

10. Hamada $Y$, Hayakawa T, Hattori H, Mikawa H. Inhibitor of nitric oxide synthesis reduces hypoxic-ischemic brain damage in the nconatal rat. Pediatr Res 1994:35:10-4.

11. Trifiletti RR. Neuroprotective effects of NG-nitric-L-arginine in focal stroke in the 7-day old rat. Eur $\mathrm{J}$ Pharmacol 1992;218:197-98.

12. Bellinger DC, Jonas RA, Rappaport LA, et al. Developmental and neurologic status of children after heart surgery with hypothermic circulatory arrest or low-flow cardiopulmonary bypass. N Engl J Med 1995;332:549-55.

13. Palmer R, Ashton D, Moncada S. Vascular endothelial cells synthesize nitric oxide from L-arginine. Nature 1988;333: 664-6.

14. Dwyer MA, Bredt DS, Snyder SD. Nitric oxide synthase: irreversible inhibition by L-NG-nitroarginine in brain in vivo and in vitro. Biochem Biophys Res Commun 1991;176:113641.

15. Kawata H, Fackler JC, Aoki M, Tsuji MK, Sawatari K, Offutt $\mathrm{M}$, et al. Recovery of cerebral blood flow and energy state in piglets after hypothermic circulatory arrest versus recovery after low-flow bypass. J Thorac Cardiovasc Surg 1993;106: 671-85.

16. Aoki M, Nomura F, Stromski M, Tsuji MK, Fackler JC, Hickey PR, et al. Effects of MK-801 and NBQX on acute recovery of piglet cerebral metabolism after hypothermic circulatory arrest. J Cereb Blood Flow Metab 1994;14:156-65.

17. Kirklin JW, Barratt-Boyes BG. Hypothermia, circulatory arrest, and cardiopulmonary bypass. In: Cardiac surgery, New York: Churchill Livingstone, 1992.

18. Heymann MA, Payne BD, Hoffman JE, Rudolph AM. Blood flow measurements with radionuclide-labeled particles. Prog Cardiovasc Dis 1977;20:55-79.

19. Chapman A, Westerberg E, Siesjo B. The metabolism or purine and pyrimidine nucleotides during insulin-induced hypoglycemia and recovery. J Neurochem 1981;36:179-89.

20. Kost GJ. pH standardization for phosphorus-31 magnetic resonance heart spectroscopy at different temperatures. Magn Reson Med 1990;14:496-506.

21. Wyatt JS, Cope M, Delpy DT, Wray S, Reynold EO. Quantification of cerebral oxygenation and haemodynamics in sick newborn infants by near infrared spectroscopy. Lancet 1986 ; 2:1063-6.

22. Van der Zee P, Delpy DT. Methods of quantitating cerebral near infrared spectroscopy data. Adv Exp Med Biol 1988; 222:183-9.

23. Cope M, Delpy D, Wray S, Wyatt J, Reynolds E. Quantitation of pathlength in optical spectroscopy. Adv Exp Med Biol 1989;248:41-6.

24. Hiramatsu T, Miura T, Forbess J, du Plessis A, Holtzman D, Jonas R. L-NAME blocks recovery of cerebral energy state after deep hypothermic circulatory arrest in piglets. In: Krieglstein J, Oberpichler-Schwenk, editors: Pharmacology of cerebral ischemia. Stuttgart: Wissenschaftliche Verlagsgesellschaft, 1994:343-54.

25. Rubolo G, Greco E, Speziale G, Tritapepe L, Marino B. Nitric oxide formation during cardiopulmonary bypass. Ann Thorac Surg 1994;57:1055-7.

26. Furlong B, Henderson AH, Lewis MJ, Smith JA. Endothelium-derived relaxing factor inhibits in vitro platelet aggregation. Br J Pharmacol 1987;90:687-92.

27. McCall T, White BJR, Boughton-Smith NK, Moncada S. Inhibition of FMLP-induced aggregation of rabbit neutrophils by nitric oxide. Br J Pharmacol 1988;85:517P.

28. Rubanyi GM, Ho EH, Cantor EH, Lumma WC, ParkerBotelho LH. Inactivation of superoxide radicals produced by human leukocytes. Biochem Biophys Res Commun 1991;181: 1392-7.

29. Furchgott RF. Role of endothelium in response of vascular smooth muscle. Circ Res 1983;53:557-73.

30. Lipton SA, Choi YB, Pan ZH, Lei SZ, Chen HS, Sucher NJ, et al. A redox based mechanism for the neuroprotective and neurodestructive effects of nitric oxide and related nitrosocompounds. Nature 1993;364:626-32.

31. Stamler JS, Singel DJ, Loscalzo J. Biochemistry of nitric oxide and its redox-activated forms. Science 1992;258:1898902. 